\title{
A REPRESENTAÇÃO DA LITERATURA COMO ARQUIVO DA DITADURA MILITAR NO BRASIL EM VOCE VAI VOLTAR PARA MIM E OUTROS CONTOS, DE BERNARDO KUCINSKI
}

\author{
Andre Rezende Benatti \\ Gisele Oliveira de Morais ${ }^{* *}$
}

\begin{abstract}
RESUMO: O presente trabalho tem como objetivo apresentar os resultados parciais da pesquisa realizada acerca da literatura como arquivo da ditadura militar Brasileira e como essa literatura é representada pelo autor Bernardo Kucinski em seu livro Você vai voltar para mim e outros contos (2014). O período da ditadura militar no Brasil foi marcado entre outros fatos pela censura artística em destaque a literária. Os eventos ocorridos destacados por denúncias de cárcere, tortura, abusos físicos, sexuais e emocionais, e os desaparecimentos de presos políticos, ainda são tratados com grande cuidado literário, apesar de toda liberdade de escrita dos dias atuais. A abordagem da pesquisa tem o apreço aos registros realizados, principalmente pelos que sobreviveram a esse período e que por sua vez se configuram enquanto obras literárias e contos que ficam resignados como arquivos de memórias, subsídios e também de elementos para o conhecimento de toda essa história. Com a pesquisa ficou a conclusão de que esses elementos, ou seja, a literatura construída nesse regime ou por ele, se configura a construção da memória de toda uma sociedade.
\end{abstract}

PALAVRAS-CHAVE: Literatura; Arquivo; Contos; Ditadura militar.

\section{Introdução}

A pesquisa realizada tem o apreço de destacar a literatura relacionada a ditadura militar brasileira e que fica construída como arquivo de memória tanto das famílias, quanto de toda a sociedade brasileira. A ditadura militar veio a postular um momento bastante negativo na história da evolução da sociedade brasileira, um período pouco superior a três décadas, mas que em toda a sua existência deixou um enorme rastro de dor e de sangue que não tem como ser apagado.

Este período foi um dos mais tensos e história brasileira e ficou marcado pela falta de liberdade, tortura, desaparecimentos dos opositores políticos e do governo autoritário. Ao

\footnotetext{
* Doutor em Letras Neolatinas pela Universidade Federal do Rio de Janeiro (UFRJ). Professor da Universidade Estadual de Mato Grosso do Sul (UEMS).

** Mestranda em Letras pela Universidade Estadual de Mato Grosso do Sul (UEMS).
} 
final desses longos 21 anos nos deparamos com inúmeras mortes e desaparecimentos. Essa ditadura foi representada com autoritarismo e repressão.

A pesquisa no seu momento inicial traz uma perspectiva histórica do conteúdo relacionado a ditadura militar, desde o golpe de 1964, os atos institucionais e a queda do regime com o processo de democratização da República Brasileira.

No segundo momento a pesquisa faz a remessa ao arquivo como um elemento de memória de toda uma sociedade, bem como os seus modos, elencando ainda a premissa condicionada a compreensão de Jacques Derrida. Continuando a abordagem referente a literatura enquanto arquivo aos olhares atentos de Andrade (2015), Derrida (2001) e Figueiredo (2017).

No último momento é verificada a inclinação a obra de Bernardo Kucinski que nos seus contos retratou a história desse período da ditadura militar, com um apreço que resgatam as memórias e substanciam de forma direta como arquivo literário dessa história brasileira. Este trabalho vai aprofundar o estudo da literatura, história e memória relacionado a resistência referente a ditadura militar brasileira. Discorrendo sobre o papel importante dessa literatura de ditadura.

\section{Ditadura militar no Brasil e as tentativas de apagamento}

Os arquivos na dinâmica discorrida sobre Jacques Derrida e a visão freudiana, é muito recorrente de estabelecer a última inclinação de Derrida sobre o Mal de Arquivo e a sua contraposição sobre a crítica da memória, é cabível a menção sobre a literatura que se configura enquanto memória, antenada ao contexto da ditadura militar no Brasil.

O período da ditadura militar no Brasil teve início no ano de 1964 com o golpe militar a partir de acontecimentos relevantes como da renúncia do então presidente Jânio Quadros no ano de 1961 (CHIAVENATO, 1997; HABERT, 1994). Após a renúncia de Jânio, assume o poder o então vice-presidente João Goulart que em meio as suas ações ocasionaram no Brasil uma crise político-econômica gerando instabilidades, e então a tomada do poder pelos militares, no ano de 1964, quando João Goulart não se sustentava mais no poder, perdendo o apoio tanto popular quanto político, e principalmente dos militares (CHIAVENATO, 1997; HABERT, 1994).

Neste momento da história brasileira, a ditadura militar teve início com o Primeiro Ato Institucional decertado em 09 de abril de 1964, denominado de AI-1. O referido ato institucional após derrubada de João Goulart no primeiro momento teve a compatibilização de postular o mandato presidencial para o presidente da Câmara dos Deputados, que a época 
estava ao encargo de Ranieri Mazilli e que posteriormente em prazo determinado deveria convocar outro pleito eleitoral (TORRES, 2016).

Entretanto isso não veio a ocorrer, a intervenção militar tomou uma ação mais veemente e com isso foi formada uma junta governamental contendo Rademaker Grünewald, Correia de Melo e Costa e Silva que por sua vez oficializaram o AI-2 que extingui os partidos e moldando todo o Legislativo brasileiro, cassando os mandatos dos políticos, bem como as eleições indiretas empossando Castelo Branco como presidente (TORRES, 2016; CALICCHIO, 2009).

Na sequência o AI-3 ao rol da Lei no 4.737/65 foi editado, e estabeleceu eleições também na modalidade indireta para o governo das Unidades Federativas, eleitos no ano de 1966, e depois os novos deputados federais e senadores. As assembleias estaduais foram extintas, a cassação demasiada e absurda dos políticos de oposição, e ainda no ano de 1966 a nova constituinte e a edição do AI-4 votando a nova Constituição de 1967 (CALICCHIO, 2009).

Na perspectiva de Calicchio (2009) os ditames da ditadura militar em 13 de dezembro de 1968, foi decretado o famoso AI-5, e este foi o ato mais contestado até os dias de hoje, nesse ato foi dada autonomia total ao presidente, e foi fechado o congresso, logo toda e qualquer oposição ao regime - agora no âmbito federal - atingindo os senadores. AI-5 foi o ato mais duro do regime militar, como uma expressão tão autoritária e vigorando até os anos de 1978 trazendo consigo ações de conteúdo exacerbadamente arbitrários e de igual modo duradouros. Neste ato o poder foi outorgado aos governos punições de conteúdo severos a quem que fosse contrário ao regime.

A ditadura militar e seus horrores durariam efetivamente até o ano de $1985 \mathrm{com}$ as eleições diretas, e encerrando esse período na história brasileira, ademais esse período deixou evidente uma notória mancha na história.

\section{Arquivo: lugar de memórias}

A literatura é totalmente presente na sociedade e proficuamente relacionada com o viés evocado ao conteúdo evolutivo, logo a presença da literatura traz a correspondência de abrir horizontes, agregar conhecimentos e destacar ainda a condição de fornecer elementos de parâmetros críticos.

Derrida (2001, p. 11 e 12) argumenta:

Arkhê, lembremos, designa ao mesmo tempo o começo e o comando. Este nome coordena aparentemente dois princípios em um: o princípio da natureza ou da história, ali onde as coisas começam [...] -, mas também o princípio da lei ali onde 
se exerce a autoridade, a ordem social, nesse lugar a partir do qual a ordem é dada [...].

De certa maneira, o vocábulo (arquivo) remete bastante bem, como temos razões de acreditar, ao arkhê no sentido físico, histórico ou ontológico; isto é, ao originário, ao primeiro, ao principal, ao primitivo em suma, ao começo. Porém, ainda mais, ou antes ainda, "arquivo" remete ao arkhê no sentido nomológico, ao arkhê do comando.

Na mesma linha, Bradley (1999, p. 108) expõe:

O arquivo é um repositório de memórias: individuais e coletivas, oficiais e não oficiais, lícitas e ilícitas, legitimadoras e subversivas. E, com base em tais memórias, nós lutamos, ainda que parcialmente e sem sucesso, para reconstruir, restaurar e recuperar o passado, para apresentar e re-apresentar histórias do passado $[\ldots]$.

Tendo a inclinação aos modos de arquivo Derrida (2001) explica que Freud traz como definição o vocábulo Verdrängung. Entretanto o autor revela que sobre a noção de arquivo, é crível destacar duas formas de compreensão, uma que tem a base de um depósito de dados na forma impressa que fornecem fatos probatórios e que por sua vez consolidam uma verdade evidenciada, deixando assim como inolvidável (DERRIDA, 2001).

A partir desta percepção do autor então o arquivo é como um instrumento - por assim dizer - que indicam tanto os fatos quanto os acontecimentos e informações sobre determinado assunto, servindo como mecanismo para investigações. Nesta premissa o arquivo é cotejado como guarda e como proteção.

Quando a remessa é direcionada a especificação acerca do mal de arquivo, um expoente a ser considerado é Jacques Derrida, e também é impreterível uma observação sobre o arquivo propriamente dito, bem como sua mensuração. De plano inicial Fasolino (2014) menciona que o arquivo em sua configuração mais preservada tem a tratativa de todos os seus males relacionados a obra Freudiana.

Segundo Fasolino (2014) os arquivos ainda trazem consigo uma contemplação em restar caracterizado, principalmente por meio do momento tecnológico em que a sociedade segue instalada, ele, o arquivo assume uma conceituação de em todo e a qualquer momento a disponibilidade no tocante a sua apreciação.

Noutra compreensão, o arquivo pode ser dimensionado, diretamente na concepção de Derrida (2001) a noção de tela, sendo assim que a tela é um arquivo. Reforçando essa menção de Derrida, Solis (2014, p. 375) acrescenta: “A tela é um arquivo, mas numa tela desconstrucionista a dimensão arquivística não é mais compreendida como repositório fechado, como fichário inerte, mas, ao contrário, como abertura, como movimento e por vir”.

Haja vista essa abordagem proferida ao teor dos conhecimentos de Derrida, demonstra o arquivo nas compreensões abordadas como objeto de guarda e depósito, traz um 
paramento de um penhor para utilização futura, e como tela é apresentado como uma projeção. Portanto o arquivo delineado nessas duas dinâmicas é de forma contumaz como uma funcionalidade que tanto aquele que arquiva como aquele que pinta ou mesmo projeta, resultando em ambas as dinâmicas a atenção de promover a apreciação de fatos, seus conhecimentos e a sua significação.

$\mathrm{Na}$ atenção de Derrida o Mal de Arquivo é existente como uma expressão pronunciada a partir da observação de Freud, todavia a leitura traça um liame histórico e também inserido na contemporaneidade. O primeiro sugere de forma intrínseca as desconstruções acerca dos registros históricos, entretanto na obra é sugerida a análise tendo o ponto inicial a memória, e retomando-a em face a contemporaneidade o aparato de inovações principalmente tecnológicas e científicas, elucidando a sua repercussão na psicanalise (TELLES, 2002). Nesta senda a exposição de Solis (2014, p. 375) retrata que:

\begin{abstract}
Mal de Arquivo estabelece como nome um jogo com o contexto histórico contemporâneo, o contexto dos "desastres que marcaram o fim do milênio", no qual estão em discussão os Arquivos do Mal, arquivos durante tanto tempo interditados, desviados, dissimulados, quando não destruídos. A prova dos horrores praticados pela dominação nazista e o holocausto; os atuais genocídios (diariamente, eles são noticiados) promovidos constantemente pelas intensas guerras em vários lugares do mundo, em geral incentivados pelos interesses escusos das potências interessadas em petróleo, venda de armas etc.; a perseguição aos Estados fora da lei, com a política intervencionista americana, a instituição da globalização etc.
\end{abstract}

Derrida que cotejou o Mal de Arquivo como uma impressão de Freud explora o sentido do arquivo em toda a sua abrangência com a disposição de origem e poder, que faz a relação direta como uma memória em aspecto material, tanto pessoal quanto histórico. A impressão Freudiana tem na análise de Derrida uma especificidade ao entendimento de arquivo que perpassa pela sua desconstrução e pelo seu processo de arquivamento, alinhado até mesmo pelo seu inconsciente (DERRIDA, 2001). O arquivo, conferindo a abordagem de Derrida traz a direção em que na psicanálise o arquivo sobressai a memória, e noutro plano a pulsão do arquivo, ao que sugere Solis (2014, p. 375):

(...) sendo um modelo de registro exterior do aparelho psíquico, arquivo do recalque — sob a pulsão de destruição, aparece a pulsão de arquivo. Segundo, o arquivamento da própria psicanálise, sua prática institucional e clínica, com seus aspectos de publicação e tradução.

O Mal de Arquivo tem a sua relação direta a pulsão de morte, como o apagamento da memória por assim ser dito, e também na repressão da memória, que por outro lado é a busca daquilo que ficou perdido. Nesse sentido Macedo (2009, p. 177) discorre: 
Ao relacionar a noção de arquivo com a memória (pessoal e histórica), o autor argumenta que há uma constante tensão entre a manutenção e repressão (consciente ou inconsciente) da memória. $\mathrm{O}$ mal de arquivo estaria ligado à pulsão de morte, ao apagamento da memória, cujas consequências podem ser psíquicas, sociais e políticas.

O Mal de Arquivo como ressoa Falosino (2014) tem o seu retorno avençado ao seu significado; Birman (2008) descreve que a obra de Derrida tem a análise principal em deixar evidente que todo o compêndio histórico fica resignado ao arquivo, e contendo ainda uma espécie de crítica, tendo então a discussão dobre o arquivo em si.

Haja vista o entendimento da versão clássica remetida ao arquivo, traz no Mal de Arquivo evocado por Derrida como que uma contraposição, pois a crítica exsurge em que o artigo não é somente aquele destinado a exposição e a memória, e ou o retorno às origens, a representatividade do Mal de Arquivo fica concatenada a uma noção história e contemporânea, e que assoberba questões de caráter tanto éticos, quanto políticos. Portanto, quando se traz a contextualização do arquivo de memórias, é muito pertinente ressaltar o conteúdo tecnológico e científico, ao passo que Derrida ao ponto de vista de Freud demonstra essa análise.

$\mathrm{Na}$ perspectiva da literatura enquanto arquivo tem uma remessa direta de ser configurada como elemento da memória literária, ou seja, o arquivo se encontra intrinsecamente relacionado a memória. Este viés é vislumbrado como compreende Andrade (2015, p. 102) que "O mundo globalizado é permeado por uma série de formas de arquivos" e na mesma premissa a memória tem a sua construção concatenada a "subjetividade do indivíduo" (p. 102).

Considerando essa dinâmica a memória ao ser preservada tem a pertinência de forma tênue com o arquivo, assim sendo a literatura deve coexistir nesses termos. Facilmente a percepção de que a literatura é visualizada como segmento da cultura propriamente dita, e a sua preservação intensifica um tipo de resgate fortalecendo a memória.

Ainda tendo o enfoque de Derrida (2001) o arquivo vem a ser relacionado de forma conceitual e comum, e somente em momento posterior é aprofundado e colocado como elemento responsável pelas memórias. Todavia o mais preciso destaque que é consoante a relação literatura e arquivo deve ser considerado o aspecto da escrita, que é materializada como arquivo e o interesse é desde o século XIX, desse modo o arquivo na escrita e propriamente na literatura tem a inclinação da escrita a partir de um olhar e a criação exposta por meio da obra em aspecto material.

Andrade (2015) informa que a vivência na era da memória é concatenada a convivência do arquivo, mas na concepção de Derrida (2001) o autor já mencionou uma diferenciação 
entre um e outro, sendo que a memória por sua vez tem a referência direta aos pressupostos pessoais de um determinado indivíduo, assim sendo um elemento totalmente social. Corroborando Andrade (2015, p. 107) leciona: “A memória é feita de registros e de apagamentos marcados por questões subjetivas e coletivas. $\mathrm{O}$ arquivo acontece para evitar que a memória seja levada ao apagamento". A memória como afirma Meneses (2007) produz uma espécie de recuperação das vivências.

Noutro aspecto o arquivo traz consigo uma vertente que contém uma duplicidade que é evocada ao arquivo em âmbito histórico, mas também contextual, relacionado entre a ideia de origem e de ordenamento. Nesta perspectiva, o arquivo tem sua delimitação relacionada a “(...) um lugar, à valores e à verdades a partir de uma escolha subjetiva da interpretação dos objetos pertencentes aquele arquivo" (ANDRADE, 2015, p. 107). Ainda Derrida (2001, p. 22) ressalta: "Não há arquivo sem um lugar de consignação, sem uma técnica de repetição e sem uma certa exterioridade. Não há arquivo sem exterior”.

Destarte a averiguação da literatura como arquivo perpassa na seguinte lógica, é sabido que os arquivos literários têm o próprio registro, e ao que se pesa aquele que pesquisa tem no arquivo o registro confiável e verídico por meio do arquivo ao conteúdo proposto e acumulado pelo ente que é configurado como literato (CAVALHEIRO; TROITÑO; 2013). Desta forma essa relação é totalmente perceptível em que o arquivo são as fontes do literato, sua obra, sua produção e suas verdades levando ao conhecimento necessário, tendo o arquivo como mecanismo em proporcionar o conhecimento pretendido em face ao conteúdo literário.

\section{Literatura e arquivo: a representação da ditadura militar nos contos de Bernardo Ku- cinski}

O jornalista e professor aposentado da USP Bernard Kucinski (1937), que nasceu em São Paulo e descende de uma família de judeus imigrantes da Polônia. O escritor escreve contos ficcionais, considerados contos policiais, que põe em evidência os diversos tipos de violência (policial, social, psicológica). O autor nos convida no desfecho de cada conto para realizarmos uma reflexão e deixar em nossas memórias histórias de torturas, traumas e desaparecimentos. Para que fique em nossas memórias e que não aconteça novamente.

Kucinski e um autor contemporâneo, publicou, no ano de 2014, o livro Você vai voltar para mim e outros contos, com vinte e oito contos que tem como tema principal a ditadura militar no Brasil e a repressão dos militares. A composição desses contos deixa em evidência 
o sentimento, o trauma das vítimas e as memórias que perduram na pele dos que viveram os anos da repressão militar.

Essa narrativa contemporânea instiga seus leitores com seus contos com tom de humor, luto e trauma. Mostrando em sua composição as protagonistas e seus traumas e como resistiram a essa ditadura. Kucinski transformou sofrimento e indignação em uma literatura de arquivo, literatura de arquivo da ditadura militar brasileira.

O autor através de seus 28 contos apresenta personagens com sequelas das torturas físicas e psicológicas sofridas por um regime autoritário do período. Famílias que nunca puderam enterrar seus entes queridos e personagens perseguidos por suas ideologias. Essas cenas retratadas deixam em nossas memórias um pouco do sentimento de cada vítima.

A literatura enquanto arquivo, bem como a relação alinhada ao conteúdo de memória, e tendo a ditadura militar como um grande expoente que fez a remessa de que a literatura dos arquivos dessa época perfaz em todo o compêndio dos arquivos de memórias.

O conto você vai voltar pra mim traz o julgamento de uma moça que é presa pelo regime militar e sofreu todas as atrocidades possíveis, só não morreu por causa de uma audiência, mesmo querendo a todo tempo morrer, talvez por causa de todo o sofrimento vivenciado. Situações como abusos sexuais, tortura física e mental, são ainda apresentados ficam em evidencia. Veja o caso do fechamento do conto, o retorno da personagem ao presídio, no momento do destaque da frase do carcereiro:

\footnotetext{
[d]e novo está só no camburão. Percebe que é o mesmo que a trouxe e se inquieta. Passa a observar o trajeto pela grade de ventilação. Vê, aterrorizada, entrarem pelo mesmo portão através do qual haviam saído para o tribunal. O camburão para,a porta se abre. O torturador diz, sorrindo: - Eu disse que você ia voltar pra mim, não disse? Vem benzinho, vamos brincar um pouco. Ele a agarra e a arrasta para fora. Os outros em volta riem. (KUCINSKI, 2014, p. 71)
}

Este retorno não finaliza a história como o pleno esperado de proteção a personagem, ou alguma forma de tratamento punitivo ao carcereiro/torturador, ele concede uma expectativa de ação que fica por conta do leitor, o que teria acontecido com a prisioneira? Esta condição nos remete a possíveis questões: ela teria se matado como prometeu durante o interrogatório? Ela teria sofrido novos abusos pelo torturador? Ela teve proteção e foi transferida para outro presídio?

Pode-se considerar que este tipo de relação auto interpretativa no desfecho do conto seria o grande destaque do livro de Kucinski. Mas apesar da expectativa de fechamento ser um ponto chave de destaque, é importante destacar o quadro de relatos subjetivos feitos pela personagem. 
Tortura, abusos físicos e emocionais, marcas de cárcere, depoimentos forjados são destaques centrais do conto que apresentam inclusive um outro eixo de livre interpretação, a ausência do nome da prisioneira. Durante todo o conto, a prisioneira é denominada de "Ela", permitindo uma interpretação de um ato comum a diferentes presos políticos.

Teve uma audiência curta, com todos os momentos cabíveis num longa-metragem, se declarou a frente de todos como inocente, declarou a tortura sofrida em todas as condições possíveis, e que somente se declara culpada em face a esta razão.

$\mathrm{Na}$ sua declaração ao seu torturador de que nunca mais voltaria, pois preferia cabalmente a sua morte, e isso de tudo ela faria para ocorrer, entretanto, o juiz ordena sua volta ao presídio, conduzida ao camburão, não vai para o presídio como o juiz "sentenciara", sua volta é para o mesmo local, resumida a voz do torturador com requintes de ironia: "Eu disse que você ia voltar pra mim, não disse? Vem, benzinho, vamos brincar um pouco" (KUCISNKI, 2014, p. 42).

É interessante destacar que ao tratarmos do livro como forma integral os contos em geral apresentam nomes e destaque de lugares, ainda considerando nomes fictícios. A ausência de nome específico, permite uma identificação universalizada à personagem que poderia ser qualquer prisioneira(o) político durante a repressão do mesmo modo que os tratamentos de tortura e repressão descritos seriam comuns a qualquer preso político durante o período.

A riqueza da literatura de Kucinski possibilitando livres interpretações diante do conto Você Vai Voltar Pra Mim, complementada pelos relatos de tortura e cárcere. Kucinski busca apresentar e representar a importância da literatura como arquivo da ditadura brasileira. É de suma importância resgatar a memória, tortura, morte e resistência das vítimas que sofreram com a repressão desse Estado autoritário. Colaborando assim para o nosso real entendimento e exaltação da comoção

Ao contemplar o processo de construção dessa literatura como arquivo da ditadura militar e destacar o peso da memória das vítimas traumatizadas e resistentes, Figueiredo (2017) destacada textos literários que são arquivos da ditadura militar e que registraram em seu enredo o período desse trauma com personagens resistentes. O livro de Figueiredo (2017) A literatura como arquivo da ditadura brasileira é a combinação perfeita entre a literatura de arquivo, relato pessoal e memória. Tempos difíceis que precisam ser lembrados para que não aconteça novamente. 


\title{
Considerações finais
}

A abordagem conferida no presente artigo fez referência a literatura como arquivo de memórias, haja vista o pano de fundo foi remetido a ditadura militar ocorrida no Brasil no ano de 1964 e que trouxe vários horrores, muita dor, perdas significativas para muitas famílias brasileiras.

Esses horrores e toda essa dor até hoje em muitos casos nada foi solucionado ainda as cicatrizes permeiam o inconsciente de muitas pessoas, sejam sobreviventes ou mesmo aqueles que vivenciaram tendo o sumiço de familiares, pais, mães, filhos, filhas, sobrinhos, amigos e muito mais.

Esse momento trazido a história brasileira serviu de combustível aos arquivos e a literatura como uma válvula de escape daqueles que sobreviveram, ou então daqueles que perderam um ente querido a manifestação de tais ocorrências e a ressalva ao conhecimento de todos.

Nesta temática levantada, a literatura enquanto arquivo da ditadura militar trouxe à tona relatos que evidenciaram esse período lastimável da história brasileira, e assim além da informação, base de dados para pesquisas e história dos acontecimentos e de igual modo a solução de alguns casos.

De forma conclusiva essa abordagem traz uma inclinação que erige a literatura como mecanismo de memória de uma sociedade, aos relatos realizados montam e mostram todas as memórias da época da ditadura, e que substancialmente ainda se tinha na memória e então no conto e, por conseguinte na literatura configurada como arquivo e sendo assim, deveras, muito importante a toda a sociedade em geral e como instrumentos de conhecimentos, pesquisa e de memória.

\section{THE REPRESENTATION OF LITERATURE AS A FILEM OF MILITARY DICTATORSHIP IN BRAZIL IN VOCE VAI VOLTAR PARA MIM E OUTROS CONTOS, BY BERNARDO KUCINSKI}

\begin{abstract}
The present work aims to present the partial results of the research carried out on literature as an archive of the Brazilian military dictatorship and how this literature is represented by the author Bernardo Kucinski in his book You will return to me and other tales (2014). The period of the military dictatorship in Brazil was marked, among other things, by artistic censorship, especially literary. The events that occurred highlighted by denunciations of imprisonment, torture, physical, sexual and emotional abuse, and the disappearances of political prisoners, are still treated with great literary care, despite all the freedom of writing today. The research approach has an appreciation for the records made, mainly by those who survived this period and which in turn are configured as literary works and tales that are resigned as archives of memories, subsidies and also elements for the knowledge of this whole history. . With the research was the conclusion that these elements, that is, the literature built in this regime or by it, is configured to build the memory of an entire society.
\end{abstract}

KEYWORDS: Literature; Archive; Tales; Military dictatorship. 


\section{REFERÊNCIAS}

ADORNO, Theodor W. Palestra sobre lírica e sociedade. In: Notas de literatura I. São Paulo: Duas Cidades; ed. 34, 2003.

ANDRADE, Gabriela Lopes Vasconcellos de. A transformação de um jacaré: Literatura, arquivo, memória e cultura de consumo. Revista Ecos. vol. 18, Ano XII, nº 01 (2015). Disponível em: <https://periodicos.unemat.br/index.php/ecos/article/view/682/648> Acesso em: 05 ago, 2020.

BIRMAN, Joel. Arquivo e Mal de Arquivo: Uma leitura de Derrida sobre Freud. Nat. hum. v.10 n.1 São Paulo jun. 2008. Disponível em: < http://pepsic.bvsa-

lud.org/scielo.php?script $=$ sci arttext\&pid $=\$ 1517-24302008000100005>$. Acesso em: 30 jul, 2020.

BRADLEY, Harriet. The Seductions of the Archive: Voices lost and found. History of the Human Sciences, v. 1, n. 2, p. 107-122. London; Thousand Oaks, CA; New Delhi: SAGE Publications, 1999.

CALICCHIO, Vera. Atos Institucionais. (2009). Disponível em:

$<$ http://www.fgv.br/cpdoc/acervo/dicionarios/verbete-tematico/atos-institucionais>. Acesso em: 03 ago, 2020.

CANDIDO, A. Literatura e sociedade: estudos de teoria e história literária. 7. ed. São Paulo: Nacional, 1985.

CAVALHEIRO, Marcos Ulisses; TROITÑO, Sonia. Arquivo e Literatura: perspectivas de acesso e difusão da memória literária no Brasil. Archeion Online, João Pessoa, v.1, n.1, p. 45-52, jul./dez. 2013. Disponível em: < https://periodicos.ufpb.br/ojs/index.php/archeion/article/view/17136/9751> Acesso em: 05 ago, 2020.

CHIAVENATO, Júlio José. O golpe de 64 e a ditadura militar. São Paulo: Editora Moderna, 1997.

DERRIDA, J. Mal de arquivo. Uma impressão freudiana. Tradução de Cláudia de Moraes Rego. Rio de Janeiro: Relumé Dumará, 2001.

FARIA, Daniel Luporini. Resenha do livro: Literatura e Sociedade de Antônio Cândido. Revista Travessias. Vol 6 No 2 - 2012. $15^{\text {a }}$ edição. p. 485-489. Disponível em: < $\underline{\text { http://e-re- }}$ vista.unioeste.br/index.php/travessias/article/view/6780/5230>. Acesso em: 04 ago, 2020.

FASOLINO, Ruben Carmine. Derrida, Freud e o retorno do arquivo. Revista de filosofia. Princípios, UFRN, CCHLA. v.21, n. 35, jan./jun. 2014, Natal (RN). EDUFRN - Editora da UFRN, 2014. Revista semestral 1. Filosofia. - Periódicos. p. 63-83. Disponível em: $<$ https://periodicos.ufrn.br/principios/article/view/6043/4795>. Acesso em: 30 jul, 2020.

FIGUEIREDO, Eurídice. A literatura como arquivo da ditatura brasileira. Rio de Janeiro: 7 Letras, 2017.

HABERT, Nadine. A década de 70: Apogeu e crise da ditadura militar brasileira. São Paulo: Editora Ática, 1994.

KUCINSKI, Bernardo. Você vai voltar pra mim - E outros contos. São Paulo: Cosac Naify. $1^{\text {a }}$ edição eletrônica, 2014.

LICARIÃO, Berttoni Cláudio. Eurídice Figueiredo - A literatura como arquivo da ditadura brasileira. Estudos de literatura brasileira contemporânea, n. 53, p. 437-442, jan./abr. 2018. 
MACEDO, Silvana. Mal de Arquivo: a dinâmica do arquivo na Arte Contemporânea. Revista Crítica Cultural. Volume 4. Número 2. p. 177-191. Dezembro de 2009. Disponível em: $<$ http://www.portaldeperiodicos.unisul.br/index.php/Critica_Cultural/article/view/141/155>. Acesso em: 30 jul, 2020.

SELIGMANN-SILVA, Márcio. Narrar o trauma - a questão dos testemunhos de catástrofes históricas. In: Revista Psicologia Clinica. Rio de Janeiro: 2008, vol. 20, n.1, p. 65-82.

MENESES, Ulpiano Bezerra de. Os paradoxos da memória. In: Memória e cultura: a importância da memória na formação cultural humana. São Paulo: Edições SESC-SP, 2007. p. 13-33.

NETO, Paulo Bungart. As memórias dos torturados pela ditadura militar brasileiras: $\mathrm{O}$ testemunho dos sobreviventes. (2015). Disponível em: <https://abralic.org.br/anais/arquivos/2015_1456107140.pdf>. Acesso em: 03 ago, 2020.

OTSUKA, Edu Teruki. Literatura e sociedade hoje. Literatura E Sociedade. Universidade de São Paulo (USP) - 14 (12), 104-115. Disponível em: <http://www.revistas.usp.br/ls/article/view/25293/27038>. Acesso em: 04 ago, 2020.

SOLIS, Dirce Eleonora Nigro. Tela desconstrucionista: arquivo e mal de arquivo a partir de Jacques Derrida. Rev. Filos., Aurora, Curitiba, v. 26, n. 38, p. 373-389, jan./jun. 2014. Disponível em: <https://periodicos.pucpr.br/index.php/aurora/article/view/1096/1021>. Acesso em: 30 jul, 2020.

TELLES, Sérgio. Mal de Arquivo - As vicissitudes da memória segundo Derrida. Psychiatry on line Brasil. Fevereiro de 2002 - Vol.7 - No 2. Disponível em:

<http://www.polbr.med.br/ano02/psi0202.php>. Acesso em: 30 jul, 2020.

TORRES, Mateus Gamba. O primeiro Ato Institucional: Carlos Medeiros Silva e o STF no pós-Golpe de 1964. Passagens. Revista Internacional de História Política e Cultura Jurídica. Rio de Janeiro: vol. 8, no.3, setembro-dezembro, 2016, p. 489-505. Disponível em: <http://www.revistapassagens.uff.br/index.php/Passagens/article/view/109/119. Acesso em: 03 ago, 2020.

Recebido em: 21/03/2021.

Aprovado em: 02/06/2021. 